\title{
Serologische Studien mit Hilfe der «optischen Methode».
}

VIII. Mitteilung.

Von

Emil Abderhalden und Carl Brahm.

Mit drei Tafeln.

(Aus dem physiologischen Institut der tierärztlichen Hochschule, Berlin.)

(Der Redaktion zugegangen am 19. Dezember 1909.)

In einer Reihe von Versuchen ist gezeigt worden, da $\beta$ nach parenteraler Zufuhr von Proteinen und von Peptonen im Plasma Fermente auftreten, die Peptone und auch Proteine abbauen. Diese Fermente erwiesen sich als nicht spezifisch, d. h. sie waren wohl auf Körper der Klasse der Proteine eingestellt, nicht aber auf ein einzelnes Protein resp. Pepton. Wir haben diese Versuche nun auch auf Kohlenhydrate ausgedehnt. In zahlreichen Versuchen konnte zunächst nachgewiesen werden, daß normales Serum vom erwachsenen Hunde weder Stärke, Rohrzucker, Raffinose noch Milchzucker abbaut. Wurde dem Hunde parenteral Rohrzucker zugeführt, so trat nach Zusatz von Serum eines in dieser Weise vorbehandelten Hundes zu einer Rohrzuckerlösung ein im Laufe der Zeit stark zunehmende Änderung des Drehungsvermögens der Gesamtlösung auf. Die zunächst stark positive Drehung nahm beständig ab und ging dann in eine Linksdrehung über. Offenbar war eine Spaltung des Rohrzuckers in Dextrose und Lävulose erfolgt.

Während es bei den Versuchen mit Eiweiß und Peptonen stets glückte, im Plasma Fermentwirkung zu erzeugen, ergaben sich bei den Versuchen mit Rohrzucker und mit Kohlenhydraten überhaupt Schwierigkeiten. Es zeigte sich, daß der Nachweis von Fermenten von verschiedenen Umständen abhängig ist. Nach wiederholten Injektionen von Rohrzucker erwies sich das Serum oft als vollständig inaktiv. Ferner verschwand das Vermögen, Rohrzucker zu spalten, bald nach der erfolgten Injektion. Bei den ersten Versuchen hatten wir unbewußt stets die 
richtigen Verhältnisse getroffen. Die Resultate waren eindeutig und stets positiv. Bei späteren Versuchen versuchten wir durch mehrere, aufeinanderfolgende Injektionen den Gehalt des Plasmas an rohrzuckerspaltenden Fermenten zu steigern. Das Serum erwies sich in diesem Fällen als fast inaktiv, $d . h$. die Drehung fiel zunächst und blieb dann fast konstant. Die gleiche Beobachtung machten wir, wenn wir das Blut längere Zeit nach der erfolgten Injektion des Rohrzuckers entnahmen. Es liegt hier eine Lücke in unseren Versuchen vor, die wir erst ausfüllen können, wenn es uns geglückt sein wird, den Abbau des Rohrzuckers nicht nur polarimetrisch, sondern durch die Isolierung der Spaltprodukte genau zu verfolgen. Erwähnt sei noch, daß das Serum auch nach längerem Erwärmen auf $60^{\circ}$. sich noch aktiv erwies. Es trat jedoch eine erhebliche Abschwächung der Wirksamkeit ein.

Die folgenden Kurven geben einen Überblick über den Verlauf einiger Versuche. Vgl. Versuch I u. II.

Das zu diesen Versuchen benutzte Versuchstier, eine schwarzweiße Spitzhündin, wog beim Beginn des Versuches $6000 \mathrm{~g}$. Es wurde ihr am 5. X. $091 \mathrm{~g}$ Rohrzucker, in $10 \mathrm{ccm}$ Kochsalzlösung gelöst, subcutan injiziert. Am 6., 7. und 8. X. erhielt das Versuchstier die gleiche Menge Rohrzucker subcutan und am 11. X. $2 \mathrm{~g}$ Rohrzucker. Am 12. X. wurden $50 \mathrm{ccm}$ Blut entnommen. Mit dem Serum dieser Blutprobe wurde Versuch I ausgeführt. Am 14. X. 09 erhielt die Hündin $2 \mathrm{~g}$ Rohrzucker in $10 \mathrm{ccm}$ physiologischer Kochsalzlösung, am 16. X. $5 \mathrm{~g}$ und ebensoviel Rohrzucker am 18. X. 09. Am 19. X. wurde Blut entnommen. Vgl. hierzu Versuch II. Dem gleichen Hund injizierten wir am 22. X. und 23. X. je $5 \mathrm{~g}$ Rohrzucker. Mit dem am 24. X. entnommenen Blut ist Versuch III ausgeführt. Versuch IV zeigt einen Inaktivierungsversuch. Das Serum wurde $1 / 2$ Stunde auf $60^{\circ}$ erwärmt.

Erwähnt sei noch, daß der Urin große Mengen von Rohrzucker enthielt, und daß wir große Schwierigkeiten hatten, hämoglobinfreies Serum zu erhalten. Bei allen Versuchen wurde das Serum stets verworfen, wenn es auch nur eine Spur von Hämoglobin aufwies. 
$\mathrm{Zu}$ einem weiteren Versuche diente ein Terrier. Körpergewicht $7000 \mathrm{~g}$. Er erhielt am 1., 3. und 6. XI. $0910,0 \mathrm{~g}$ Rohrzucker subcutan. Das am 9. XI. entnommene Blut ergab ein Serum, das den zugesetzten Rohrzucker nicht angriff. Am 13. XI. und 14. XI. injizierten wir 5 g Rohrzucker. Das Serum des am 15. XI. entnommenen Blutes war aktiv, wie Versuch $\mathrm{V}$ zeigt.

$\mathrm{Zu}$ weiteren Versuchen verwendeten wir einen $11400 \mathrm{~g}$ schweren deutschen Pinscher. Er erhielt am 19. und 22. XI. 09 $5 \mathrm{~g}$ Rohrzucker. Das am 23. XI. 09 gewonnene Serum erwies sich als inaktiv. Am 24. XI. verabreichten wir wieder $5 \mathrm{~g}$ Rohrzucker subcutan. Das Resultat war wieder völlig negativ.

$\mathrm{Zu}$ Versuch VI diente ein $7200 \mathrm{~g}$ schwerer Terrier. Er erhielt am 7. XII. 09 abends 7 Uhr $5 \mathrm{~g}$ Rohrzucker subcutan. Am 8. XII. morgens 9 Uhr 30 Min. wurde Blut entnommen. Eine Spaltung war nicht zu beobachten. Die Injektion wurde am 8. XII. abends $7 \mathrm{Uhr}$ wiederholt und zwar mit $10 \mathrm{~g}$ Rohrzucker. Der Hund wog $5950 \mathrm{~g}$. Am 9. XII. wurde abends $7 \mathrm{Uthr}$ Blut entnommen. Das Serum erwies sich wiederum als inaktiv. Nun injizierten wir am 9., 10. und 12. XII. je $5 \mathrm{~g}$ Rohrzucker. Mit dem am 13. XII. gewonnenen Serum ist der Versuch VI ausgeführt.

Wir haben noch eine größere Anzahl von derartigen Versuchen ausgeführt, um festzustellen, unter welchen Bedingungen sich das Auftreten von Fermenten konstant feststellen läßt, jedoch bis jetzt ohne Erfolg. Bald war eine Spaltung nachweisbar, bald blieb die Anfangsdrehung ganz konstant. Es sind auch Versuche mit Serum von normalen Hunden ausgeführt worden. Es zeigte sich in keinem Falle auch nur eine Andeutung einer Spaltung. Versuch VII zeigt ein Beispiel für einen solchen Kontrollversuch.

In einer weiteren Reihe von Versuchen injizierten wir lösliche Stärke subcutan. Ihre Lösung reduzierte Fehlingsche Lösung stark. Zu diesen Versuchen wurde ein brauner Bastard verwendet. Sein Gewicht betrug $12400 \mathrm{~g}$. Er erhielt am 8. X. 09 $1 \mathrm{~g}$ Stärke, am 13: X. $2 \mathrm{~g}$, am 14. X. $2 \mathrm{~g}$ und am 16. X. 1,5 g Stärke subcutan. Am 19. X. wurde Blut entnommen. Vgl. Ver- 
such VIII. Am 21. und 22. X. gaben wir wieder $2 \mathrm{~g}$ Stärke. Das Serum des am 24. X. entnommenen Blutes spaltete Rohrzucker ganz erheblich. Vgl. Versuch IX. Beim 1/2 stündigen Erwärmen auf $60^{\circ}$ nahm das Spaltungsvermögen dieses Serums beträchtlich ab. Vgl. Versuch X.

Wir haben endlich noch Versuche mit Raffinose, Milchzucker und mit $\alpha$ - und $\beta$-Methylglukosid begonnen. Über diese von Herrn Dr. Mühsam durchgeführten Versuche soll demnächst berichtet werden.

Aus den vorliegenden Versuchen ergibt sich, daß nach subcutaner Zufuhr von «artfremden» Kohlenhydraten - Rohrzucker, Stärke - und von Kohlenhydraten, die «blutfremd"-Milchzucker - sind, d. h. die normalerweise nicht im Blut enthalten sind, das Plasma resp. Serum Eigenschaften annimmt, die vor den Injektionen dieser Kohlenhydratarten nicht nachweisbar sind. Alles deutet daraufhin, daß Fermente auftreten, die die genannten Zuckerarten in ihre Komponenten zerlegen. Wir haben auch hier gewissermaßen eine in die Blutbahn verlegte "Verdauung». Daß der Organismus hierbei nicht imstande ist, die zugeführten Stoffe im vollen Umfange auszunützen, beweist der reichliche Übertritt der genannten Kohlenhydrate in den Harn.

Es wird unsere weitere Aufgabe sein, in exakter Weise festzustellen, ob tatsächlich eine Hydrolyse der genannten Kohlenhydrate unter der Einwirkung von Serum vorbehandelter Tiere eintritt. Ferner werden wir den Nachweis zu führen haben, ob es sich hier um spezifische, auf eine bestimmte Kohlenhydratart eingestellte Fermente handelt. Die bisherigen Ergebnisse ergeben keine Spezifizität.

Erwähnt sei noch, daß wir nach subcutaner Injektion von Aminosäuren bis jetzt noch keine auf Eiweiß oder Peptone eingestellte Fermente im Serum nachweisen konnten. Bei Einführung von Polypeptiden erhielten wir wechselnde Resultate. Wir kommen auf diese Versuche noch zurück. 